\title{
Interleukin 6: from bench to bedside
}

Norihiro Nishimoto and Tadamitsu Kishimoto

Nature Clinical Practice Rheumatology (2006) 2: 619-626 [doi:10.1038/ncprheum0338]

doi:10.1038/ncprheum0372

\section{ERRATUM}

In the November 2006 issue, the competing interests statement of the authors of this Review was omitted. The competing interests statement should have appeared as
"N Nishimoto declared associations with the following company: Chugai Pharmaceutical. T Kishimoto holds a patent for tocilizumab. See the article online for further details of these competing interests."

\section{Don't miss the following articles that will soon be appearing in the pages of Nature Clinical Practice Rheumatology:}

\section{PRACTICE POINTS}

Alendronate versus alfacalcidol in the prevention of glucocorticoid-induced bone loss

Bevra H Hahn and Theodore J Hahn

Do antirheumatic drugs increase the risk of acute myocardial infarction?

Sherine E Gabriel

\section{REVIEWS}

Technology Insight: the role of color and power Doppler ultrasonography in rheumatology Wolfgang A Schmidt

Mechanisms of Disease: leukotrienes and lipoxins in scleroderma lung disease - recent insights and potential therapeutic implications

Otylia Kowal-Bielecka, Krzysztof Kowal, Oliver Distler and Steffen Gay

Please note that the title details are not finalized and might be subject to change.

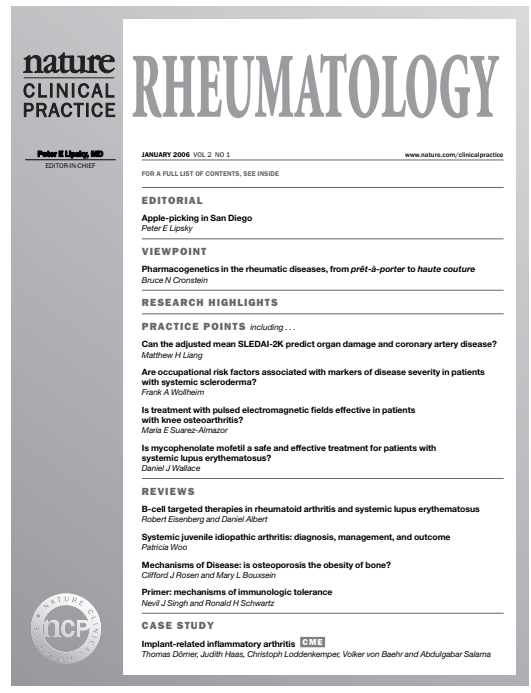

